\title{
REVIEW
}

\section{CREATIVITY AND CAPTURE: ORGANIZING FOR THE COMMERCIAL APPLICATION OF SCIENCE AND TECHNOLOGY}

\section{S. HILL}

Centre for Research Policy, University of Wollongong, P.O. Box 1114, Wollongong, NSW 2500, Australia.

\section{The Developing Countries Situation Today}

In parallel with the way in which the past decades have seen a worldwide change in attitudes towards the process of innovation, there has also been a change in the way that Research and Development is judged and organized.

The 1960s was the age of scientific research, a time when both in advanced and developing countries, science was seen as the solution for economic and social problems. During the 1970s a scries of world events heralded the end of an age of perceived infinite expansion: the Club of Rome report that identified environmental limits to growth; the 1983 OPEC world oil crisis that heralded limits to cheap energy; and the computer-led technological change that presented major constraints on expanding employment opportunitics. Science itself contracted into what the British scientist John Ziman described as a steady state, i.e. where expansion of resources devoted to scientific enquiry plateaued. The 1980s followed and reflected a time when science was increasingly pushed into the background behind technological advantage; where research organization was increasingly subject to commercial corporation rules, performance evaluation and 'bottom-line' linancial thinking. During the 1980s the science-push view of research within developing countries was, in parallel, displaced by what could be called a demand-pull application model: i.e. the view of organizing science moved increasingly from one that emphasized building science institutions in the belief that they would eventually contribute to economic success, to one that emphasized heeding industry's necds.

As we move into the 1990s, we enter a knowledge decade, and an information decade. The two themes are not identical. Knowledge implies creativity; information implies capture. Creativity implies organizations that allow knowledge play, capture implies organizations that allow cfficient information gathering, translation and use, which was one of the prime capabilities of Japan, and is increasingly now of Korean commercial organizations. The fronticr of the 1990s worldwide is likely to be the way that knowledge and information is organized, a phenomenon that implies innovative new organizational principles, and not bottom-line managerialist approaches of the 1980s. 
Developing countries should learn from the international trends and not be captured by them - particularly, as has often been the case, captured by what the more advanced nations did ten years before.

Developing countries reside in an entirely different technological context to advanced industrial nations. In advanced nations research is embedded in a commercial context which is technologically skilled and receptive. Industrial technological change is continuous and incremental, so new research fits into a iearnt process. In developing countries, innovation is considerably more alien; and technological capacities in industry are likely to be generally either more dependent or non-existent. Developing countries research enterprise (largely a government responsibility) must therefore develop the receptivitity of the commercial environment as well as of the capability of the research itself.

Developing countrics research stands as a minor player in a continuous stream of technological change that is injected into the national economy from outside, largeiy through multinational commercial interests. It cannot expect to make major changes to the economic welfare of the nation; just to shape the process to the advantage of the nation.

On the other hand, rescarch in developing countries provides the only platform for some level of control by the nation over the shape of technological influences that govern its development. No other interest, for 'example, is going to 'link' together sectors that are split from each other when higher technology enters the economy, unable to use the factor inputs that lower quality previous production could produce. No other interest will build a research or skills infrastructure from which local commercial enterprise can dip for its own innovative or problem-solving needs. Similarly, indigenous research capability is necessary as a resource to deal with environmental issues, to adapt nationally-relevant technologies, and to save cost on, for example, medical or government-purchased infrastructure developments. In particular, it will be impossible for a nation to capture the information it needs for its own productive adaptation and performance unless it has the organizational and skill resources that can do so. In other words, when we look at the organization of research in the 1990s for developing countries we should not only look narrowly at commercialism, but also at other outcomes as well.

Also however, we should pay attention to the environment of the 1990s. This is an environment where organization is likely to provide an essential key to both effective knowledge creation and information capture. Developing countries should therefore look towards the latest organization design principles associated with innovation, remembering in the process the specific and different situation in which their own science and technology research is located. Developing countries should release themselves from copying old models and a tendency to focus on the latest technologies 
and fashionable fields of research (e.g. biotechnology, electronics, robotics, etc.) and pay a lot more attention to the new organizational design principles that provide the real competitive advantage in the oncoming era.

\section{Principles that Follow in Organizational Design for Research in Developing Countries}

A number of design conditions follow directly from the observation of the different situation in developing countries vis a vis advanced nations.

The first concerns linkages. By far the majority of research in developing countries will remain within government. Its role will primarily be to galvanize the productive sector across organizational and cultural boundaries, i.e. boundaries between government and research and commcrcial productive enterprise. Equally, the topics of concern in government research must pay attention to the linkages within. the economy (often technologicaily based) that private commercial enterprise either pays no attention to, or directly breaks by its commercially-interested action.

To act to establish organizational linkages implies bridging quite different organizational cultures, with quite different organizational values and structures of authority and procedure. For example, the market-oriented culture is likely to pay more attention than the knowledge-oriented culture to profit rather than pursuit of technical knowledge; to reward organizational rather than professional status; to authority based on executive power and position rather than knowledge-based status; to hierarchical procedures rather than collegiate procedures; to short rather than long time-scales, etc. Linkage therefore implies careful organizational and cultural practice.

Linkage also implies information and knowledge of each other's concerns. Whilst information systems help and liaison units may act as a bridge, it must also be ciear that what is involved is a process of connection, not information provided by others. In other words, the design is of contact (including geographically-stimulated) rather than of orders and abstract information.

The second major design considcration for research in developing countries concerns the targetting of research. Again, in keeping with the innovative 1990s organization dictum, whilst targetting involves effective use of appropriate information, attention must be paid to the organizational process. In project selection, attention neęds to be paid to good leadership. Management of people in a creative research environment cannot be by control, restriction or fear - by hierarchical power; but by leadership of people, trust, and management of the process of their relationships in producing research together in such a way that results link directly with productive use. 
Design should therfore be thought of as design of research organization space, not of hierarchy, control and continual supervision. Information systems are implied in both project selection and management. But the information is ultimately for the research people to use rather than for managers to use to tell them what to do. Design of information therefore is of self-reporting procedures and organizatior reporting procedures. Performance indicators can be used, but should on the one hand inclucie assessment of the particular impact the organization is seeking (eg. application of research rather than reports about what could be applied); and on the other hand, be used in full recognition that what is likely to be more valuable is the participation of researchers in designing the criteria by which their organizational performance wil! be assessed. If targetting is the aim, design is also therefore of the information space that ensures that researchers are aware of the project mission; and of the sense of urgency that is associated with it. These factors should be incorporated into the organization design (and therefore, into expectations and self-motivation) rather than be commands of hierarchical control.

This leads us directly to the design considerations that follow from review of the latest approaches to innovative organization internationally.

Of all the lessons that have emerged over the years about research organization, the principle one concerns research leadership. Research is ultimately bounded play. It can only occur with those who know how to play this particular game, and particularly are cognizant of where the boundaries lie; who feel free to play; and who are willing to participate. Research creativity - at whatever level - cannot be commanded. Its space however, can be shaped; and the motivation of actors within this space can be influenced. This is the task of research leadership, a very different phenomenon from 'bottom-line' management and control.

Therefore, the first principle for research organization is to create the right environment for research. This implies promoting group processes rather than hierarchical grid processes (to follow a distinction that Mary Douglas, a famous contemporary anthropologist, makes about the major organizing principles of all societies). Boundaries between people need to be defined very carefully so that people can operate as autonomously as possible within and cause as little tension as possible to those outside. Inspiration rather than control is the leader's mechanism; building capabilities - picking the right people, building teams, theoretical vitality, ideas, etc. - is a critical resource strategy; resourcing and motivating those that perform within their organizational space and who are required to meet criteria of urgency is essential. Micanwhile, wider organizational support for the research enterprise is important. The attitudes of the chief executive and more senior officials or managers must allow for some lcvel of autonomy and trust, whilst still attaching the research enterprise to performance criteria by a longer rope than would be required 
for activity that did not involve uncertainty and performance that could be measured on a day-to-day basis.

The other key area oî organizational theory that is important for developing research design for the 1990 s concerns organizationa! culture. Virtually all that the present report has been pronosing concerns building culture, or the patterning of values, relations, statuses, boundaries, meanings and objectives of research organization. The focus of space design is basicaily to design create the fabric of the organization rather than its rather colder, harder information and control skeleton.

Developing a contemporary research culture requires balancing a number of conflicting cultural sets or tensions. These particuiarly involve the tension between marke: or commercia: orientations and knowledge-generating interests; between meanings, siatuses and values that are associated with power and authority in the immediate organization vs. those associated with international science, etc. These alternate culture tensions have to be managed within any contemporary research organization. They are particularly relevant in developing countries research organizations as there is very little room for slippage in organizational purpose when resources are so limitci.

Depending on how these tensions are managed, and particularly how the group vs. grid environments of rescarch spacc are managed, varying types of culture will emerge: One way of classifying the results is in terms of excellent, fuzzy or awful cultures. Excellent cultures have a clear and shared mission, and goals that inflitrate to the lowest levels of the organization. Fuzzy cultures tend to be characterized by defensive strategies; concem with maintaining the status quo and low distribution of shared knowledge about what he organization is seeking to achieve. Awful cultures tend be associated with continuous crisis, confusion amongst employees about direction; and frustrated and unpleasant employees. The key continuum betwecn excellent anc awful is from resilient and innovative to fragile and rigid.

The literature on innovative organization then makes it clear that resilient and innovative cultures are associated with organization design space that emphasizes group building rather than ego-competitive strategies; trust rather than fear; participation rather than control; dealing with conflicts rather than letting personal and emotional problems persist. Culture can be changed towards resilient and innovative design. However, to do so requires paying attention to the three key entry points where culture is constituted (in any socieiy or organization), that is in the social relations people enter into to produce; in the knowledge that is valued and rewarded in producing together; and in the symbols that make sense of, and reward peoples' actions when producing together. Designing innovative space takes these three key factors into account. 


\section{Conclusions}

Research in the 1990s is in the 1990s. It rests within an entirely different externai environment than it did even over the last decade. The key dimensions of these environmental constraints concern the control, use and transfer of knowledige; restrictions on what national research can produce in terms of national benefits; and opportunites that exist within the international economy.

The situation for developng countries is likely to remain one where the body of research responsibility will continue to lie with government. Government's role is therefore to galvanize productive activity in the nation's interests through its research enterprise - within the constraints that the international economy and technological power resources impose. With this in mind, government is not only concerned with direct commercial stimulus, but also with building appropriate infrastructures that commerce can 'dip' into both for a skilled labour force and for direct research; with research on national issues that no foreign interest is likely to pay attention to, in particular, ensuring linkage between the varying sectors of the economy, and ensuring adequate attention is paid to environmental concerns; with general knowledge and skill resources that ensure saving of costs and choice in technological strategies. Government is however also concerned with stimulating and resourcing commerciai enterprise directly, and this involves building bridges across institutional walls; targetting scarce activily; developing innovative organization; and carefully monitoring intellectual property rights and providing assistance to local production facilities to gain maximum advantage out of any innovative activity they pursue.

The keys to organization that follow involve the use of information and control in management, but not according to the solutions of the 1980s. Instead, the emphasis is on building 'group' over 'grid' process in organization; fostering 'bounded play' within research organization; building organizations that create innovative research cultures, and also create bridges to 'use' cultures.

To do this involves building the social relations of creativity, not letting them happen by accident; designing culture space. Emphasis needs to be placed on organization leadership and managing the entry points for cultural change - i.e. through designing the social relations of production, rewarding the knowledge that specifically matters to the organization's desired performance; paying attention to the symbols that tell others of what meanings matter; and at the same time, being conscious of the development of power that is based on authority connected with innovative purpose rather than hicrarchical and executive authority as such.

Commercial performance will happen in industry not government. What government can do is to create the right environment - in general policy; and in its own research enterprise tinat is appropriately linked and responsive, and which fosters the 
receptive environment in industry that government enterprise itself must have for any of its research to be applied towards the nation's productive advantage.

(Professor Stephen Hill is the Director of the Centre for Research Policy, University of Wollongong, Australia and the current Chairman of the Science and Technology Policy Asian Network - STEPAN. This article is based on material presented at the STEPAN Workshop on Managing Research Systems in Developing Countries held in Hanoi, Vietnam, in December 1992). 